TITLE:

\title{
Electrospun SrTiO3 nanofibers for photocatalytic hydrogen generation
}

$\operatorname{AUTHOR}(\mathrm{S})$ :

Macaraig, Lea; Chuangchote, Surawut; Sagawa, Takashi

\section{CITATION:}

Macaraig, Lea ...[et al]. Electrospun SrTiO3 nanofibers for photocatalytic hydrogen generation. Journal of Materials Research 2014, 29(01): 123130

ISSUE DATE:

2014-01-14

URL:

http://hdl.handle.net/2433/187122

\section{RIGHT:}

(C) Materials Research Society 2013; This is not the published version. Please cite only the published version.; この論文は出版社版でありませ ん。引用の際には出版社版をご確認ご利用ください。 


\section{Electrospun $\mathrm{SrTiO}_{3}$ Nanofibers for Photocatalytic Hydrogen Generation}

Lea Macaraig", Surawut Chuangchote", and Takashi Sagawa ${ }^{\ddagger} *$

* Graduate School of Energy Science, Kyoto University, Yoshida-honmachi, Sakyo-ku, 6068501 Kyoto, Japan

${ }^{\dagger}$ The Joint Graduate School of Energy and Environment, King Mongkut University of Technology Thonburi, 126 Prachauthit Rd., Bangmod, Tungkru, 10140 Bangkok, Thailand

*E-mail: sagawa.takashi.6n@kyoto-u.ac.jp Tel: +81 757535624 Fax: +81 757535627

KEYWORDS nanostructure, catalytic, $\mathrm{H}$

ABSTRACT. Homogenous strontium titanate $\left(\mathrm{SrTiO}_{3}\right)$ nanofibers were prepared via the electrospinning of precursor solutions with both strontium and titanium salts. Photocatalytic activities of these $\mathrm{SrTiO}_{3}$ nanofibers for hydrogen generation from water were examined and compared to that of $\mathrm{SrTiO}_{3}$ nanoparticles. The nanofibers calcined at $700{ }^{\circ} \mathrm{C}$ showed the highest photocatalytic activity of $167 \mu \mathrm{mol} \mathrm{h}^{-1} \mathrm{~g}^{-1}$ among the $\mathrm{SrTiO}_{3}$ samples tested. The high activity was attributed to the ideal stoichiometric ratio of $\mathrm{Ti} / \mathrm{Sr}$, small crystallite size, high crystallinity, 
mesoporous structure, large surface area, and appropriate energy gap. These were confirmed through field emission scanning electron microscopic with energy dispersive spectroscopic observations, X-ray diffraction patterns, $\mathrm{N}_{2}$ gas absorption-desorption isotherm measurements, photo-electron yield spectroscopy in air, and UV-visible spectrophotometry.

\section{INTRODUCTION}

Hydrogen is recognized as an alternative to fossil fuel since it has a high heat of combustion and its by-product is water instead of carbon dioxide. However, there are no significant natural deposits of hydrogen gas; thus the currently viable technologies for its production, like the reforming of natural gas or the use of electricity from renewable energy in the electrolysis of water must be improved since these methods are still inefficient in terms of carbon and energy usage. ${ }^{1}$ Among the two methods mentioned, water-splitting via electrolysis has the potential for a low carbon emission energy cycle. Interest in the development of semiconductor photocatalysts which can absorb light and convert it to an electron-hole pair in the right energy level to catalyze the direct splitting of water has increased since hydrogen was first produced from water over titanium dioxide $\left(\mathrm{TiO}_{2}\right)$ electrodes without the application of electric power. ${ }^{2}$ Strontium titanate $\left(\mathrm{SrTiO}_{3}\right)$, like anatase $\mathrm{TiO}_{2}$, has band levels suitable for photocatalytic water splitting since its valence band and conduction band is lower and higher than the oxidation-reduction levels of water respectively. But unlike $\mathrm{TiO}_{2}$, the perovskite structure of $\mathrm{SrTiO}_{3}$ facilitates for easier doping for electronic modification.,

The use of inorganic semiconductor materials in the powder form instead of bulk photoanodes have been considered due to difficulties in construction, issues of stability under light, and lower surface areas of bulk photoanodes. ${ }^{5}$ Pure $\mathrm{SrTiO}_{3}$ powders have been shown to 
evolve hydrogen in the presence of sacrificial reagents that act as hole scavengers like methanol, ${ }^{6}$ with higher evolution rates or visible light photocatalysis achieved upon metal doping. ${ }^{7,8}$ Photocatalytic decomposition of water without the use of sacrificial agents had also been reported using nickel oxide- $-{ }^{9,}{ }^{10}$ and platinum $-{ }^{11}$ loaded $\mathrm{SrTiO}_{3}$ powders. Among nanostructures, the use of a nanofiber morphology is of interest since we had previously found that anatase $\mathrm{TiO}_{2}$ nanofibers have higher hydrogen production over nanoparticles. ${ }^{12}$ However, the preparation of homogenous $\mathrm{SrTiO}_{3}$ nanofibers has been difficult. $\mathrm{SrTiO}_{3}$ nanofibers prepared via the hydrothermal reaction of electrospun $\mathrm{TiO}_{2}$ nanofiber with strontium salts have led to heterogenous structures. ${ }^{13,} 14$ In this report we improved and modified the methods for preparation and photophysical characterization of pure and homogenous $\mathrm{SrTiO}_{3}$ nanofibers via the electrospinning of precursor solutions containing both the titanium and strontium salts. We likewise examined the photocatalytic performance in terms of hydrogen production rates of $\mathrm{SrTiO}_{3}$ nanofibers prepared through the electrospinning of precursor solutions with both strontium and titanium salts.

\section{EXPERIMENTAL SECTION}

\section{Preparation of Spinning Solutions}

$\mathrm{SrTiO}_{3}$ nanofibers were prepared with a modification from the previously reported procedure. ${ }^{15}$ Instead of strontium acetylacetonate (SrAcAc), strontium acetate (SrAc, $1.3 \mathrm{~g}$, Wako) was used to prepare inorganic load solutions by mixing with equimolar amounts of titanium butoxide ( $2.0 \mathrm{~g}$; Aldrich) in acetylacteone (0.6 g; Aldrich). These solutions were then separately mixed with a solution of polyvinylpyrrolidone $\left(0.80 \mathrm{~g} ; \mathrm{M}_{\mathrm{w}}=1,300,000 ;\right.$ Aldrich; PVP) in acetic acid (10.0 mL; Wako) and stirred for $1 \mathrm{~h}$ to obtain precursor spinning solutions. 
Preparation of $\mathrm{SrTiO}_{3}$ Nanofibers

The prepared precursor solutions were then loaded into a plastic syringe with a stainless steel needle (1 cm long; 22-gauge). This needle is connected to the positive electrode of a high voltage power supply (15 V; Gamma High Voltage Research). An aluminum sheet was used as the collector plate and was set $15 \mathrm{~cm}$ away from the needle and was connected to the grounding electrode of the high voltage power supply. A syringe pump (KDScientific 100) was used to control the flow rate at $1 \mathrm{~mL} \mathrm{~h}^{-1}$. The nanofibers that were collected were exposed to atmospheric moisture for $5 \mathrm{~h}$ for complete hydrolysis. Organic content were then removed from the electrospun fibers via calcination at $500,600,700$, and $800{ }^{\circ} \mathrm{C}$ for $3 \mathrm{~h}$. The ramping time for all calcination regimes were set at 30 minutes.

\section{Characterization of $\mathrm{SrTiO}_{3}$ Nanofibers}

The prepared $\mathrm{SrTiO}_{3}$ nanofibers and a sample of commercially available $\mathrm{SrTiO}_{3}$ nanoparticles (NPs; Wako) were characterized for various properties related to hydrogen production activity. Thermogravimetry-differential thermal analysis (TG-DTA: Rigaku TG812 Thermoplus 2) was performed to determine the contents of the electrospun nanofibers after calcination. The nanofiber samples were measured against an $\mathrm{Al}_{2} \mathrm{O}_{3}$ sample under argon atmosphere. The temperature profiles for the TG-DTA analysis followed the calcination regimes used. The morphology and ratio of titanium to strontium (Ti/Sr) were characterized by fieldemission scanning electron microscopy with energy dispersive spectroscopy (FE-SEM/EDS; JEOL JSM-6500FE). X-ray diffraction (XRD; Rigaku RINT 2100) spectroscopy was used to measure crystalline properties such as relative perovskite content and crystallite size. The surface areas were estimated by the Brunauer-Emmett-Teller (BET) technique and the average pore size 
was estimated by the Non-localized Density Functional Theory (NLDFT) method from the adsorption-desorption plots obtained using an automatic water vapor adsorption apparatus (BEL Japan; BELSORP 18). The optical energy gap $\left(E_{g}\right)$ was estimated from the absorbance spectra obtained using a UV-visible spectrophotometer (Shimadzu; UV-2450) fitted with an IRS-2200 integrating sphere attachment following a modified version of the Tauc model. ${ }^{16}$ The valence band levels of the nanofibers were measured via photo-electron yield spectroscopy in air (Riken Keiki; AC-3) with the irradiating intensity of the light source set at $100 \mathrm{nW}$.

\section{Photocatalytic Hydrogen Production}

The hydrogen production activity of the nanofibers and NP samples were measured by dispersing $1 \mathrm{~g}$ of a sample in an $800 \mathrm{~mL}$ solution (40\% v/v methanol:water) inside an innerirradiation type Pyrex photoreactor with a headspace of $700 \mathrm{~mL}$. A $450 \mathrm{~W}$ high-pressure mercury lamp (Ushio; UM 452) was contained inside the inner cylindrical water-jacket cooled at $30^{\circ} \mathrm{C}$. The Pyrex water-jacket cut-off most of the ultraviolet and infrared radiation of the light source. The reactor was purged with argon gas before the start of the photoreaction and the light was stabilized for 10 min before sampling. The concentration of hydrogen and oxygen gas was measured simultaneously with the photoreaction using a gas chromatograph fitted with a thermal conductivity detector (Shimadzu; GC-8A; molecular sieve 5A; argon carrier gas).

\section{RESULTS AND DISCUSSION}

In the previously reported optimization of the spinning solution, SrAcAc was used as the strontium salt since it is soluble in a wider range of inorganic solvents. In the same optimization, acetic acid was found to be the ideal spinning solution solvent for solutions containing 20 (w/v)\% titanium salt load, equimolar amounts to titanium of strontium salt, and $8(w / v) \%$ of 
PVP polymer guide. ${ }^{15}$ In this report, SrAc was used instead as it is more soluble in acetic acid compared to SrAcAc. Through the SEM observations as shown in Figure 1, it was confirmed that the electrospun fibers from SrAc solutions were also homogenous and were without rods and beads. The average diameters of the nanofibers significantly decreased when the calcination temperature was raised from $500{ }^{\circ} \mathrm{C}$ to $600{ }^{\circ} \mathrm{C}(243 \mathrm{~nm}$ to $142 \mathrm{~nm})$. The average diameter did not change significantly with the further rise of calcination temperature to $700{ }^{\circ} \mathrm{C}$ or $800{ }^{\circ} \mathrm{C}(138$ and $136 \mathrm{~nm}$, respectively). This may be largely attributed to the degradation of the organic contents; specifically the PVP polymer guide. This is supported by the TG plots obtained for the different calcination regimes (Figure 2). The nanofibers obtained after $500{ }^{\circ} \mathrm{C}$ calcination were $44.2 \mathrm{wt} \%$ of the original while the nanofibers obtained after $600{ }^{\circ} \mathrm{C}$ were $40.7 \mathrm{wt} \%$ of the original. The nanofibers obtained after 700 and $800{ }^{\circ} \mathrm{C}$ calcination were $38.8 \mathrm{wt} \%$ and $38.6 \mathrm{wt} \%$ of the original. This indicates that the majority of the organic matter is eliminated upon calcination at $600{ }^{\circ} \mathrm{C}$ and the nanofibers calcined at $700{ }^{\circ} \mathrm{C}$ and $800{ }^{\circ} \mathrm{C}$ had most of the carbonates removed as confirmed by the prominent endothermic curves during the temperature maintaining region in the TGA plots (Figure 2). The electrospun fibers were confirmed to be of the perovskite crystalline structure of $\mathrm{SrTiO}_{3}$ via their XRD patterns (Figure 3). Samples for all calcination temperatures tested have a prominent (110) perovskite peak at $32^{\circ}$ of $2 \theta$. However, the nanofibers calcined at $500{ }^{\circ} \mathrm{C}$ have $\mathrm{SrCO}_{3}$ peaks also present in the XRD spectra with the most prominent peak at $25^{\circ}$ of 20. As the calcination temperature is further raised, the carbonate contents were removed such that the $\mathrm{SrCO}_{3}$ peaks gradually subsided in the XRD patterns of the electropsun fibers calcined at $700{ }^{\circ} \mathrm{C}$ and $800{ }^{\circ} \mathrm{C}$. The XRD patterns of the nanofibers calcined at $700{ }^{\circ} \mathrm{C}$ and $800{ }^{\circ} \mathrm{C}$ were similar to the XRD pattern of the NP sample and the $\mathrm{SrTiO}_{3}$ diffraction data of JCPDS 35-0734. The relative amount of the perovskite phase from the XRD patterns were determined from the 
peak intensities of the major characteristic peak for the perovskite $\left(2 \theta=32^{\circ}, I_{p}\right)$ and the impurity $\left(2 \theta=25^{\circ}, I_{i}\right)$ following the equation: $:^{17}$

Perovskite phase $(\mathrm{wt} \%)=100 * I_{p} /\left(I_{p}+I_{i}\right)$

The peak at $2 \theta=25^{\circ}$ was selected as the impurity peak since anatase $\mathrm{TiO}_{2}$ is also manifested at the peak. The nanofibers calcined at $500{ }^{\circ} \mathrm{C}$ contain $49.8 \mathrm{wt} \%$ perovskite. At a higher calcination temperature of $600{ }^{\circ} \mathrm{C}$, most of the organic contents were removed from the nanofibers such that the weight percent of the perovskite phase reached $98.8 \mathrm{wt} \%$. In the cases of calcination at $700{ }^{\circ} \mathrm{C}$ and $800{ }^{\circ} \mathrm{C}$, all the samples were mostly of the perovskite phase (100 wt $\%$ ) indicating that the crystalline phase of nanofibers were almost pure $\mathrm{SrTiO}_{3}$. The obtained patterns for the NP sample also shows almost an exact match of the standard diffraction data of $\mathrm{SrTiO}_{3}$, indicating that the perovskite phase of the NPs is of $100 \mathrm{wt} \%$. EDS analysis also supported the confirmation of the presence of both strontium and titanium in the nanofibers and that the atom ratio of titanium to strontium $(\mathrm{Ti} / \mathrm{Sr})$ is near to the stoichiometric ratio of 1 for the perovskite structure of $\mathrm{SrTiO}_{3}$. Figure 4b shows that the fabricated nanofibers have Ti/Sr ratios that are 0.01 to 0.13 away from the ideal stoichiometric ratio, confirming that indeed $\mathrm{SrTiO}_{3}$ nanofibers were fabricated.

The photocatalytic activities in terms of hydrogen production rate for the electrospun nanofibers calcined at $500,600,700$ and $800{ }^{\circ} \mathrm{C}$ were considerably higher $\left(81-167 \mu \mathrm{mol} \mathrm{h}^{-1} \mathrm{~g}^{-1}\right)$ than that of the NP sample $\left(32 \mu \mathrm{mol} \mathrm{h}^{-1} \mathrm{~g}^{-1}\right)$ (Figure 4a). The photocatalytic hydrogen production rate of the fibers calcined at $500{ }^{\circ} \mathrm{C}$ is $85 \mu \mathrm{mol} \mathrm{h} \mathrm{h}^{-1} \mathrm{~g}^{-1}$. The rate slightly decreased for the fibers calcined at $600{ }^{\circ} \mathrm{C}\left(81 \mu \mathrm{mol} \mathrm{h} \mathrm{g}^{-1}\right)$. The nanofibers calcined at $700{ }^{\circ} \mathrm{C}$ have the highest hydrogen production rate of $167 \mu \mathrm{mol} \mathrm{h} \mathrm{g}^{-1}$, and those calcined at $800{ }^{\circ} \mathrm{C}$ have a slightly lower activity of 
$141 \mu \mathrm{mol} \mathrm{h} \mathrm{h}^{-1}$. Electrospun nanofibers from SrAcAc were also tested for photocatalytic activity for comparison (Supporting Information 3). The best performing fibers from SrAcAc solutions were those calcined at $800{ }^{\circ} \mathrm{C}$ with a significantly lower hydrogen production rate of $14 \mu \mathrm{mol} \mathrm{h}$ ${ }^{1} \mathrm{~g}^{-1}$.

The photocatalytic activity of the $\mathrm{SrTiO}_{3}$ catalysts depends on the interplay of a number of factors that are affected by the calcination temperature. One of these factors is the stoichiometric ratio of $\mathrm{Ti}$ to $\mathrm{Sr}$. Reported $\mathrm{SrTiO}_{3}$ films were found to be more active for the photodegradation of Victoria Blue dye if the Ti/Sr ratio were more equimolar and not Ti- or Srrich. ${ }^{18}$ As can be seen in Figure 4a and 4b, the photocatalytic activity follows the inverse of the trend of the difference of $\mathrm{Ti} / \mathrm{Sr}$ ratio with the equimolar value of 1 . The NP sample with $\mathrm{Ti} / \mathrm{Sr}$ ratio of 1.35 , which was the farthest away from the stoichiometric ratio of 1 , showed the lowest activity. The electrospun nanofibers, which had closer to stoichiometric Ti/Sr ratio of 1 have higher activities. The calcined sample at $700{ }^{\circ} \mathrm{C}$ with $\mathrm{Ti} / \mathrm{Sr}$ ratio of 0.99 had the highest activity, followed by the one calcined at $800{ }^{\circ} \mathrm{C}$ with $\mathrm{Ti} / \mathrm{Sr}$ ratio of 1.03 . While the photocatalytic activities of the calcined sample at $500{ }^{\circ} \mathrm{C}$ with $\mathrm{Ti} / \mathrm{Sr}$ ratio of 1.08 , and the calcined one at $600{ }^{\circ} \mathrm{C}$ with $\mathrm{Ti} / \mathrm{Sr}$ ratio of 1.13 were relatively lower. These $\mathrm{Ti} / \mathrm{Sr}$ ratios of nanofibers from $\mathrm{SrAc}$ solutions are improvements from the Ti/Sr ratios of SrAcAc fibers $(1.36,1.37,1.33$, and 1.26 for fibers calcined at 500 to $800{ }^{\circ} \mathrm{C}$ respectively $)^{15}$. The improvement of the $\mathrm{Ti} / \mathrm{Sr}$ ratios of the nanofibers from SrAc solutions maybe due to less steric hindrance of the acetate salt compared to that of the acetylacetonate salt in the interaction with PVP and the higher solvent interaction of SrAc compared to SrAcAc.

Another factor in determining the photocatalytic activity of inorganic photocatalysts is the crystallite size. Generally, inorganic photocatalysts with smaller crystallite sizes have higher 
activities because smaller crystallite sizes can lead to quantum size effects in semiconductors. ${ }^{19}$ The trend in photocatalytic activity of the nanofibers followed the inverse of the trend of crystallite sizes (Figure $4 \mathrm{a}$ and $4 \mathrm{c}$ ). The crystallite sizes of the nanofiber samples at each calcination temperature and that of NPs were estimated from the (110) peak (Figure 2) according to the Scherrer equation. The NPs had the largest crystallite size of $49.2 \mathrm{~nm}$ and the lowest activity. The electrospun nanofibers have considerably smaller crystallite sizes than that of NPs and considerably exhibited higher activities. The crystallite size of the nanofibers generally increased with the rise in calcination temperature, from $23.6 \mathrm{~nm}$ (calcined at $500{ }^{\circ} \mathrm{C}$ ) to $26.8 \mathrm{~nm}$ $\left(800{ }^{\circ} \mathrm{C}\right)$. A relatively large increase is observed when the temperature is raised from $500{ }^{\circ} \mathrm{C}$ to $600{ }^{\circ} \mathrm{C}$. This increase is expected as a larger amount of organic content was removed from the fibers, leading to the increase in the weight percent of perovskite as confirmed by TG-DTA curves and XRD patterns. The size increase plateaued as the temperature was raised from $600{ }^{\circ} \mathrm{C}$ to $700{ }^{\circ} \mathrm{C}$ then continued to increase when the temperature was further raised to $800{ }^{\circ} \mathrm{C}$. The plateau may be due to the small difference of the perovskite phase weight percent between the nanofibers obtained after the calcination at $600{ }^{\circ} \mathrm{C}$ and $700{ }^{\circ} \mathrm{C}$. The increase of crystallite size of the nanofibers obtained after the calcination at $800{ }^{\circ} \mathrm{C}$ as compared to the case of the calcination at $700{ }^{\circ} \mathrm{C}$ may be due to the partial sintering and the growth of the fine $\mathrm{SrTiO}_{3}$ crystallites, as confirmed by the DTA curves, since all of the crystalline material is already of the perovskite phase. The largest crystallite size of the electrospun fibers from SrAc solutions is similar to the crystallite size of the best performing nanofibers from SrAcAc solutions (26.6 nm).

The trend in crystallite sizes is closely related to that in pore sizes. Inorganic materials can be macroporous/non-porous, microporous, or mesoporous. The nitrogen adsorptiondesorption isotherms of the nanofibers and NPs show that the nanofibers maybe of a mesoporous 
structure since they have the characteristics of a Type IV isotherm and that NP is of a macroporous/non-porous structure (Type II) (Figure 5). ${ }^{20}$ Mesoporous materials have been shown to have higher activity due to higher surface interaction. ${ }^{11}$ The hysteresis loop of the isotherms for all electrospun nanofibers are of the type H3. H3 loops are usually observed for materials in aggregates of plate-like particles resulting to slit-shaped pores ${ }^{20}$. The slit widths, $W$, and pore volume, $V_{P}$, of the nanofibers are obtained using NLDFT analysis. $W$ for all nanofiber samples is lower than the respective crystallite size. $W$ decreased from $2.36 \mathrm{~nm}$ to $1.18 \mathrm{~nm}$, while $V_{P}$ remained relatively constant $\left(0.094 \mathrm{~cm}^{3} \mathrm{~g}^{-1}\right.$ and $0.098 \mathrm{~cm}^{3} \mathrm{~g}^{-1}$, respectively) when the calcination temperature was raised from $500{ }^{\circ} \mathrm{C}$ to $600{ }^{\circ} \mathrm{C}$. The decrease in pore width may be due to the crystal growth as can be seen in the trend in crystallite size, while the organic content still present in both the $500{ }^{\circ} \mathrm{C}$ and the $600{ }^{\circ} \mathrm{C}$ samples may be the reason why the pore volume is stable. $W$ then increased from $1.18 \mathrm{~nm}$ to $1.95 \mathrm{~nm}$ while $V_{P}$ decreased from $0.098 \mathrm{~cm}^{3} \mathrm{~g}^{-1}$ to $0.039 \mathrm{~cm}^{3} \mathrm{~g}^{-1}$ when the calcination temperature was raised from $600{ }^{\circ} \mathrm{C}$ to $700{ }^{\circ} \mathrm{C}$. This may be due to the removal of organic content while the crystallite size remains relatively constant. A significant decrease in $W$ from $1.95 \mathrm{~nm}$ to $0.46 \mathrm{~nm}$ accompanied by a large increase in $V_{P}$ from $0.039 \mathrm{~cm}^{3} \mathrm{~g}^{-1}$ to $0.214 \mathrm{~cm}^{3} \mathrm{~g}^{-1}$ can be seen when the calcination temperature was raised from 700 ${ }^{\circ} \mathrm{C}$ to $800{ }^{\circ} \mathrm{C}$. This is largely attributed to the sintering and growth of the crystallites. ${ }^{21}$ Although the $V_{P}$ of the $800{ }^{\circ} \mathrm{C}$ nanofibers is relatively larger than that of the $700{ }^{\circ} \mathrm{C}$ calcined nanofibers, a $W$ of $0.46 \mathrm{~nm}$ can only accommodate less than four water molecules passing together, which may be the reason why the activity for the sample calcined at $700{ }^{\circ} \mathrm{C}$ is higher than the activity for the one calcined at $800{ }^{\circ} \mathrm{C}$.

Another important parameter that can be measured from the adsorption-desorption isotherms is the BET surface area. Materials with high surface areas are expected to have higher 
activity because of the better contact between the electron-hole pair in the photocatalyst and the adsorbate (viz. water molecule) at the interface. ${ }^{22}$ The BET surface area of the calcined nanofiber samples decreased with rise of the calcination temperature. The decrease in BET surface area when the calcination temperature was raised from $500{ }^{\circ} \mathrm{C}$ to $700{ }^{\circ} \mathrm{C}$ is linear and is of a larger slope (from $122.0 \mathrm{~m}^{2} \mathrm{~g}^{-1}$ to $75.0 \mathrm{~m}^{2} \mathrm{~g}^{-1}$ to $31.3 \mathrm{~m}^{2} \mathrm{~g}^{-1}$ ) than the decrease from $700{ }^{\circ} \mathrm{C}$ to $800{ }^{\circ} \mathrm{C}$ (from $31.3 \mathrm{~m}^{2} \mathrm{~g}^{-1}$ to $23.5 \mathrm{~m}^{2} \mathrm{~g}^{-1}$ ). The larger slope of the decrease from $500{ }^{\circ} \mathrm{C}$ to $700{ }^{\circ} \mathrm{C}$ may be due to the removal of the organic contents, which have a larger surface area than the crystalline material. The decrease of the BET surface area from $700{ }^{\circ} \mathrm{C}$ to $800{ }^{\circ} \mathrm{C}$ may be due to the growth of the $\mathrm{SrTiO}_{3}$ crystallites, which reduces the pore volume in the material. For all the calcination temperatures tested $\left(500,600,700\right.$ and $\left.800{ }^{\circ} \mathrm{C}\right)$ the electrospun nanofibers from SrAc solutions have higher BET surface areas than nanofibers from SrAcAc solutions $\left(34.8 \mathrm{~m}^{2} \mathrm{~g}^{-1}, 23.1 \mathrm{~m}^{2} \mathrm{~g}^{-1}\right.$, $18.1 \mathrm{~m}^{2} \mathrm{~g}^{-1}$, and $16.0 \mathrm{~m}^{2} \mathrm{~g}^{-1}$ respectively $)^{15}$ and NPs $\left(16.3 \mathrm{~m}^{2} \mathrm{~g}^{-1}\right)$. Although the trend in BET surface area is decreasing with the rise of calcination temperature, nanofibers calcined at a higher temperature have a higher activity. This variance may be explained by the interplay between the trends of crystallinity and BET surface area in relation to the calcination temperature. The crystallinity generally increases with the increase in calcination temperature as some order is achieved in the initially amorphous materials. High photocatalytic activities are expected for materials with high crystallinities rather than materials with amorphous structure, since amorphous materials have been shown to lead to the recombination of the photo-generated electron-hole pair. ${ }^{21}$ The higher relative perovskite content of the samples calcined at higher temperatures may help explain the increase in photocatalytic activity with the decrease in BET surface area. This can be clearly seen in the increasing trend of hydrogen production rate per surface area unit as compared to the hydrogen production rate per mass unit (Figure 4a). The 
interplay of the decrease in BET surface area and the increase in crystallinity can help explain the decrease of the hydrogen production rate per mass unit of the $800{ }^{\circ} \mathrm{C}$ from that of the $700{ }^{\circ} \mathrm{C}$ sample.

Aside from these physical properties, the electronic band levels of the photocatalysts also affect the hydrogen production activity. Figure 6 shows the valence and conduction band levels of the calcined nanofibers and NP. The valence band is determined from the photo-electron yield spectra (Figure 7). The valence band levels for the electrospun nanofibers and the NPs are similar $\left(500{ }^{\circ} \mathrm{C}: 6.82 \pm 0.26 \mathrm{eV} ; 600{ }^{\circ} \mathrm{C}: 6.85 \pm 0.46 \mathrm{eV} ; 700{ }^{\circ} \mathrm{C}: 6.84 \pm 0.28 \mathrm{eV} ; 800{ }^{\circ} \mathrm{C}: 6.85 \pm\right.$ $0.35 \mathrm{eV}$; NPs: $6.75 \pm 0.30 \mathrm{eV}$ ), and below the oxygen oxidation level of $5.32 \mathrm{eV}$ at $\mathrm{pH}$ 7. The conduction band levels are determined from the difference of the valence band levels and the estimated $E_{g}$. The $E_{g}$ of the nanofiber samples were determined from a modified version ${ }^{16}$ of the Tauc plot technique wherein the total absorbance $A$ was plotted instead of the extinction coefficient $\alpha$ following the Tauc equation for direct transitions: $(h v \alpha)^{2}=a\left(h v-E_{g}\right)$. $\alpha$ was replaced by $A$ since from the Lambert-Beer-Bouguer law, $\alpha=\ln (10) A / d$ where $d$ is the thickness of the film which was kept constant during the measurements, thus the equation can be rewritten as $(h v A)^{2}=a^{\prime}\left(h v-E_{g}\right)$ where $a^{\prime}$ represents another constant different from $a$. The estimated $E_{g}$ for the nanofiber samples from the modified Tauc plots (Figure 7) are 3.11 $\pm 0.08 \mathrm{eV}$ for those that are calcined at $500{ }^{\circ} \mathrm{C}, 3.12 \pm 0.05 \mathrm{eV}$ for those that are calcined at $600{ }^{\circ} \mathrm{C}, 3.063 .19 \pm 0.08$ $\mathrm{eV}$ for those that are calcined at $700{ }^{\circ} \mathrm{C}$, and $3.06 \pm 0.06 \mathrm{eV}$ for those that are calcined at $800{ }^{\circ} \mathrm{C}$. Therefore the conduction band levels of the nanofibers were determined to be above the hydrogen reduction level of $4.08 \mathrm{eV}$ at $\mathrm{pH} 7$. Since the valence and conduction bands for all samples are below and above the oxygen oxidation and hydrogen reduction level at $\mathrm{pH} 7$, 
respectively, the samples with narrower $E_{g}$ are expected to have higher activity. The nanofibers calcined at a higher temperature have a slightly narrower $E_{g}$ than the nanofibers calcined at a lower temperature. This is consistent with the trend in photocatalytic activity. This narrower $E_{g}$ may be due to the presence of $\mathrm{SrCO}_{3}$ peaks in the samples calcined at a lower temperature and the higher amount of amorphous phase..$^{23}$ All the $E_{g}$ of the electrospun nanofibers though are slightly larger than that of NPs $(3.03 \pm 0.06 \mathrm{eV})$. Since other physical properties discussed above for NPs are inferior compared to that of the nanofibers, the photocatalytic activity of NPs is significantly lower than that of the nanofibers.

\section{CONCLUSIONS}

Homogenous $\mathrm{SrTiO}_{3}$ nanofibers were reproducibly prepared via the electrospinning of clear precursor solutions, which contained both the strontium and the titanium salts. Photocatalytic properties in terms of BET surface area, $\mathrm{Ti} / \mathrm{Sr}$ ratio, and crystallinity were improved when the strontium salt was changed from SrAcAc to SrAc. This improvement may be largely attributed to better interaction of the strontium salt with PVP and the acetic acid solvent. The electrospun nanofibers from SrAc solutions calcined at $700{ }^{\circ} \mathrm{C}$ gave the best photocatalytic performance of $167 \mu \mathrm{mol} \mathrm{h} \mathrm{h}^{-1} \mathrm{~g}^{-1}$ among all the calcination temperatures tested. This value is significantly higher than that of the best performing nanofibers from SrAcAc solutions with an activity of $14 \mu \mathrm{mol} \mathrm{h} \mathrm{g}^{-1}$ which is calcined at $800{ }^{\circ} \mathrm{C}$. More importantly, it is significantly higher than that of NPs with $32 \mu \mathrm{mol} \mathrm{h} \mathrm{g}^{-1}$. This is because the nanofibers electrospun nanofibers from SrAc solutions calcined at $700{ }^{\circ} \mathrm{C}$ have better if not comparable photocatalytic properties as compared to NPs. Although the electrospun nanofibers have a slightly wider $E_{g}(3.06 \mathrm{eV}$ for nanofibers calcined at $700{ }^{\circ} \mathrm{C}$ vs. $3.03 \mathrm{eV}$ for $\mathrm{NPs}$ ), the $\mathrm{Ti} / \mathrm{Sr}$ ratio is closer to the ideal 
stoichiometric ratio (0.99 for nanofibers calcined at $700{ }^{\circ} \mathrm{C}$ vs. 1.35 for NPs) and the crystallite size is smaller (23.6 nm for nanofibers calcined at $700{ }^{\circ} \mathrm{C}$ vs. $49.2 \mathrm{~nm}$ for NPs). The electrospun nanofibers are mesoporous ( $W=1.95 \mathrm{~nm}$ for nanofibers calcined at $700{ }^{\circ} \mathrm{C}$ ) as compared to the macroporous/non-porous NPs. In addition they have a larger BET surface area $\left(31.3 \mathrm{~m}^{2} \mathrm{~g}^{-1}\right.$ for nanofibers calcined at $700{ }^{\circ} \mathrm{C}$ vs. $11.6 \mathrm{~m}^{2} \mathrm{~g}^{-1}$ for NPs) and comparable crystallinity. The photocatalytic activity for hydrogen production for nanofibers calcined at $700{ }^{\circ} \mathrm{C}\left(167 \mu \mathrm{mol} \mathrm{h}^{-1} \mathrm{~g}^{-}\right.$

${ }^{1}$ ) is even higher than the reported hydrogen production of $\mathrm{TiO}_{2}$ nanoparticles (ST-01, Ishihara) and anatase nanofibers, which is attained as $18 \mu \mathrm{mol} \mathrm{h}^{-1} \mathrm{~g}^{-1}$ and $54 \mu \mathrm{mol} \mathrm{h}^{-1} \mathrm{~g}^{-1}$ respectively. ${ }^{12}$

\section{ACKNOWLEDGMENT}

The authors are indebted to Prof. Keiichi N. Ishihara and Dr. Eiji Yamasue of Graduate School of Energy Science, Kyoto University for the use of TG-DTA. This work was partly supported by the "Energy Science in the Age of Global Warming" of Global Center of Excellence (G-COE) program (J-051) of the Ministry of Education, Culture, Sports, Science and Technology (MEXT) of Japan.

\section{REFERENCES}

1. G.W. Crabtree, M.S. Dresselhaus and M.V. Buchanan: The Hydrogen Economy Physics Today. 57(12), (2004).

2. A. Fujishima and K. Honda: Electrochemical Photolysis of Water at a Semiconductor Electrode Nature. 238(5358), 37 (1972).

3. R.U.E. t Lam, L.G.J. de Haart, A.W. Wiersma, G. Blasse, A.H.A. Tinnemans and A. Mackor: The sensitization of $\mathrm{SrTiO}_{3}$ photoanodes by doping with various transition metal ions Materials Research Bulletin. 16(12), 1593 (1981).

4. X. Zhou, J. Shi and C. Li: Effect of Metal Doping on Electronic Structure and Visible Light Absorption of $\mathrm{SrTiO}_{3}$ and $\mathrm{NaTaO}_{3}$ (Metal = Mn, Fe, and $\mathrm{Co}$ ) The Journal of Physical Chemistry C. 115(16), 8305 (2011).

5. M. Ashokkumar: An overview on semiconductor particulate systems for photoproduction of hydrogen International Journal of Hydrogen Energy. 23(6), 427 (1998).

6. A. Kudo, A. Tanaka, K. Domen and T. Onishi: The effects of the calcination temperature of $\mathrm{SrTiO}_{3}$ powder on photocatalytic activities Journal of Catalysis. 111(2), 296 (1988). 
7. T. Puangpetch, T. Sreethawong and S. Chavadej: Hydrogen production over metal-loaded mesoporous-assembled $\mathrm{SrTiO}_{3}$ nanocrystal photocatalysts: Effects of metal type and loading International Journal of Hydrogen Energy. 35(13), 6531 (2010).

8. J.W. Liu, G. Chen, Z.H. Li and Z.G. Zhang: Electronic structure and visible light photocatalysis water splitting property of chromium-doped $\mathrm{SrTiO}_{3}$ Journal of Solid State Chemistry. 179(12), 3704 (2006).

9. K. Domen, S. Naito, T. Onishi and K. Tamaru: Photocatalytic decomposition of liquid water on a NiO-SrTiO 3 catalyst Chemical Physics Letters. 92(4), 433 (1982).

10. K. Domen, A. Kudo, T. Onishi, N. Kosugi and H. Kuroda: Photocatalytic decomposition of water into hydrogen and oxygen over nickel(II) oxide-strontium titanate $\left(\mathrm{SrTiO}_{3}\right)$ powder. 1. Structure of the catalysts The Journal of Physical Chemistry. 90(2), 292 (1986).

11. T. Puangpetch, T. Sreethawong, S. Yoshikawa and S. Chavadej: Hydrogen production from photocatalytic water splitting over mesoporous-assembled $\mathrm{SrTiO}_{3}$ nanocrystal-based photocatalysts Journal of Molecular Catalysis A: Chemical. 312(1-2), 97 (2009).

12. S. Chuangchote, J. Jitputti, T. Sagawa and S. Yoshikawa: Photocatalytic Activity for Hydrogen Evolution of Electrospun $\mathrm{TiO}_{2}$ Nanofibers ACS Applied Materials \& Interfaces. 1(5), 1140 (2009).

13. L. Macaraig, S. Chuangchote and T. Sagawa: Fabrication of $\mathrm{SrTiO}_{3}$ Nanofibers for Hydrogen Production MRS Proceedings. 1408, (2012).

14. T. Cao, Y. Li, C. Wang, C. Shao and Y. Liu: A Facile in Situ Hydrothermal Method to $\mathrm{SrTiO}_{3} / \mathrm{TiO}_{2}$ Nanofiber Heterostructures with High Photocatalytic Activity Langmuir. 27(6), 2946 (2011).

15. L. Macaraig, S. Chuangchote and T. Sagawa: Fabrication of Strontium Titanate Nanofibers via Electrospinning, in Zero-Carbon Energy Kyoto 2012, edited by T. Yao (Springer Verlag, Japan, Tokyo, 2013), pp. 141.

16. A. Guchhait and A.J. Pal: Copper-Diffused AgInS2 Ternary Nanocrystals in Hybrid Bulk-Heterojunction Solar Cells: Near-Infrared Active Nanophotovoltaics ACS Applied Materials \& Interfaces. 5(10), 4181 (2013).

17. R. Wongmaneerung, R. Yimnirun and S. Ananta: Effect of vibro-milling time on phase formation and particle size of lead titanate nanopowders Materials Letters. 60(12), 1447 (2006).

18. V. Subramanian, R.K. Roeder and E.E. Wolf: Synthesis and UV-Visible-Light Photoactivity of Noble-Metal- $\mathrm{SrTiO}_{3}$ Composites Industrial \& Engineering Chemistry Research. 45(7), 2187 (2006).

19. E. Roduner: Size matters: why nanomaterials are different Chemical Society Reviews. 35(7), 583 (2006).

20. K.S.W. Sing: Reporting physisorption data for gas/solid systems with special reference to the determination of surface area and porosity (Recommendations 1984) Pure and Applied Chemistry. 57(4), 603 (1985).

21. Y. Sakatani, D. Grosso, L. Nicole, C. Boissiere, G.J. de A. A. Soler-Illia and C. Sanchez: Optimised photocatalytic activity of grid-like mesoporous $\mathrm{TiO}_{2}$ films: effect of crystallinity, pore size distribution, and pore accessibility Journal of Materials Chemistry. 16(1), 77 (2006).

22. M.R. Hoffmann, S.T. Martin, W. Choi and D.W. Bahnemann: Environmental Applications of Semiconductor Photocatalysis Chemical Reviews. 95(1), 69 (1995). 
23. D. Bao, X. Yao, N. Wakiya, K. Shinozaki and N. Mizutani: Band-gap energies of sol-gelderived $\mathrm{SrTiO}_{3}$ thin films Applied Physics Letters. 79(23), 3767 (2001). 

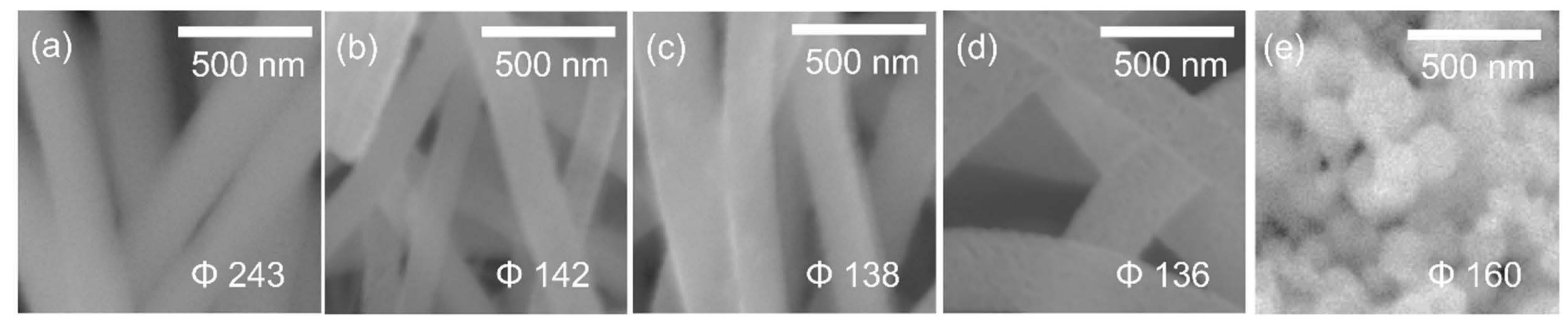

FIG.1. SEM images of the electrospun nanofibers calcined at (a) 500, (b) 600, (c) 700, and (d) $800{ }^{\circ} \mathrm{C}$ and (e) of the NP sample. The average diameters are indicated. 


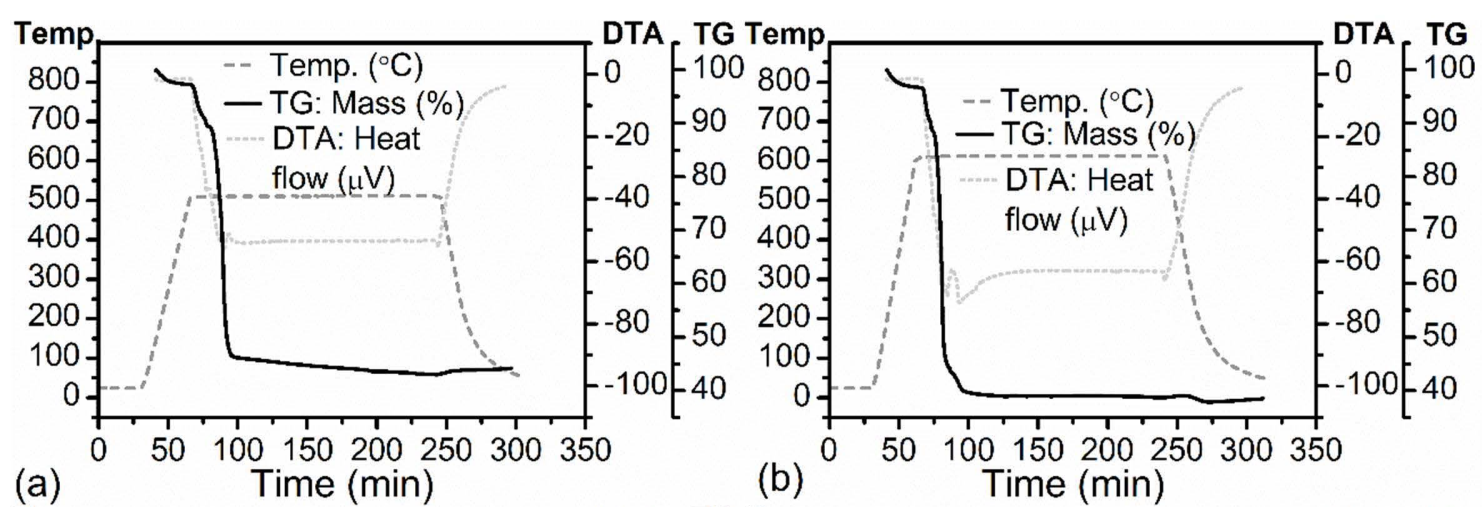

(a) Time (min)

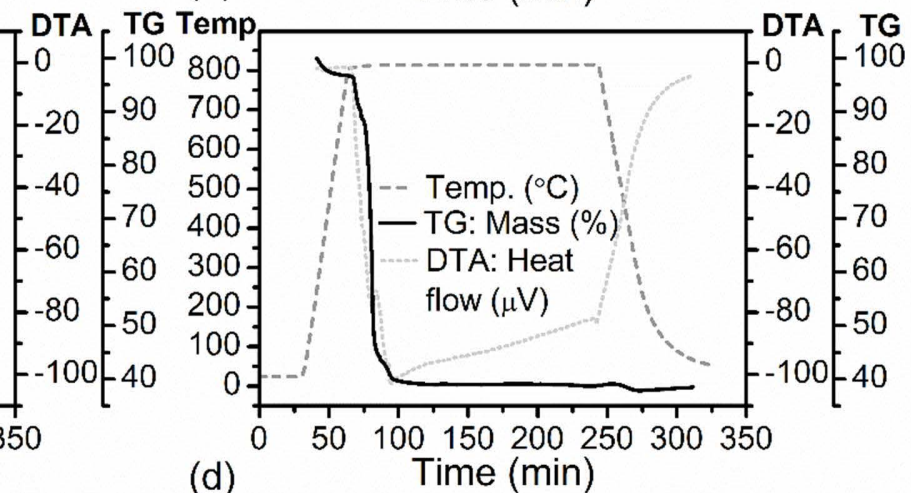

(c)

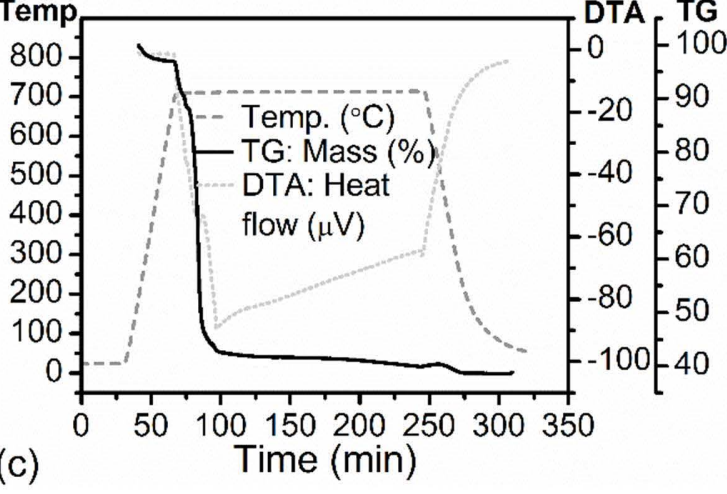

(d)

Time (min)

FIG. 2. TG-DTA plots of the electrospun fibers following the temperature regime used for calcination at (a) 500, (b) 600, (c) 700, and (d) $800{ }^{\circ} \mathrm{C}$. 


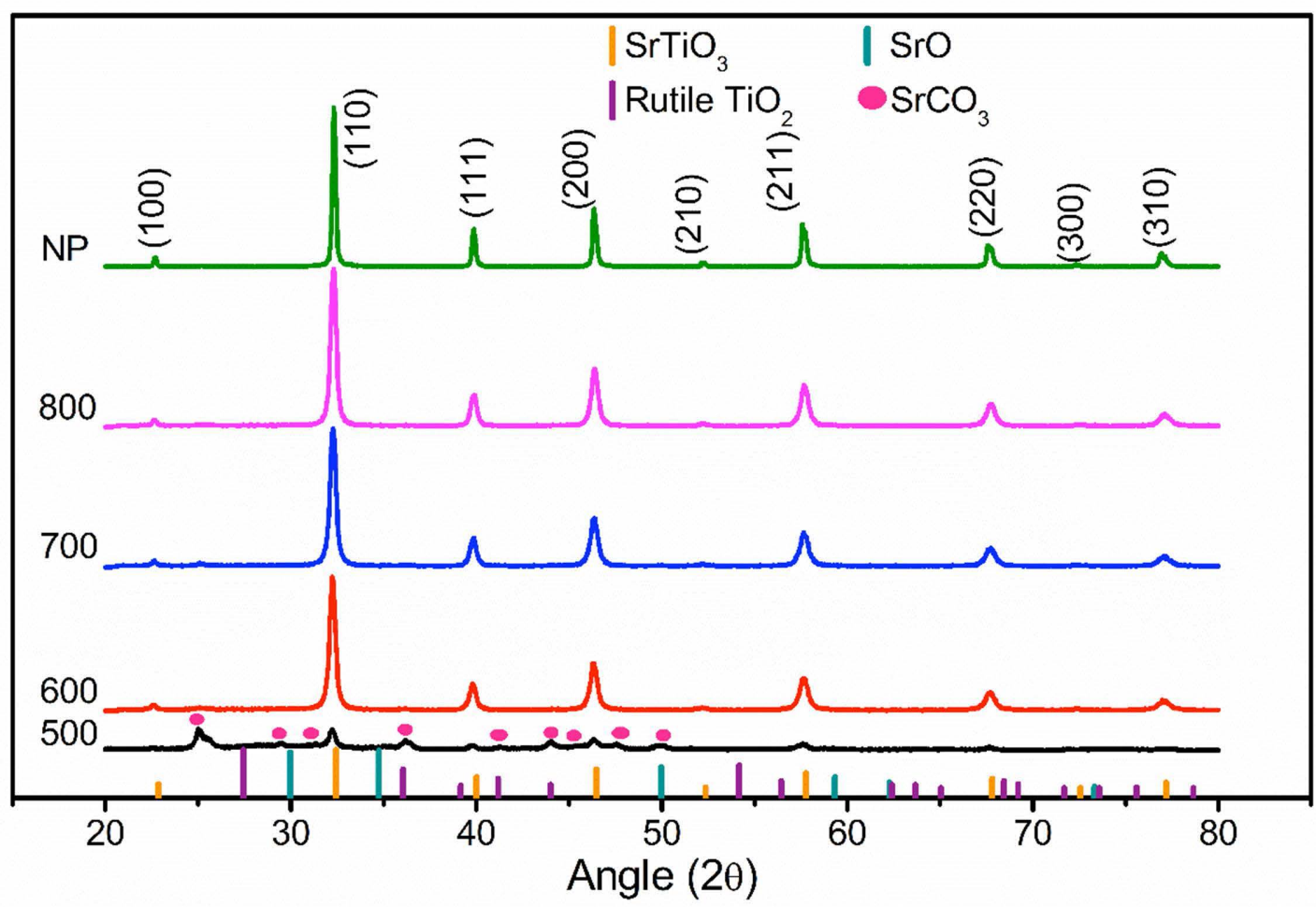

FIG. 3. XRD patterns for the electrospun nanofibers calcined at 500, 600, 700, and $800{ }^{\circ} \mathrm{C}$ and for the NP sample. Standard diffraction data of JCPDS 35-0734 for $\mathrm{SrTiO}_{3}$, JCPDS 05-0418 for $\mathrm{SrCO}_{3}$, JCPDS 12-1276 for rutile $\mathrm{TiO}_{2}$, and JCPDS 6-0510 for SrO are also marked. 

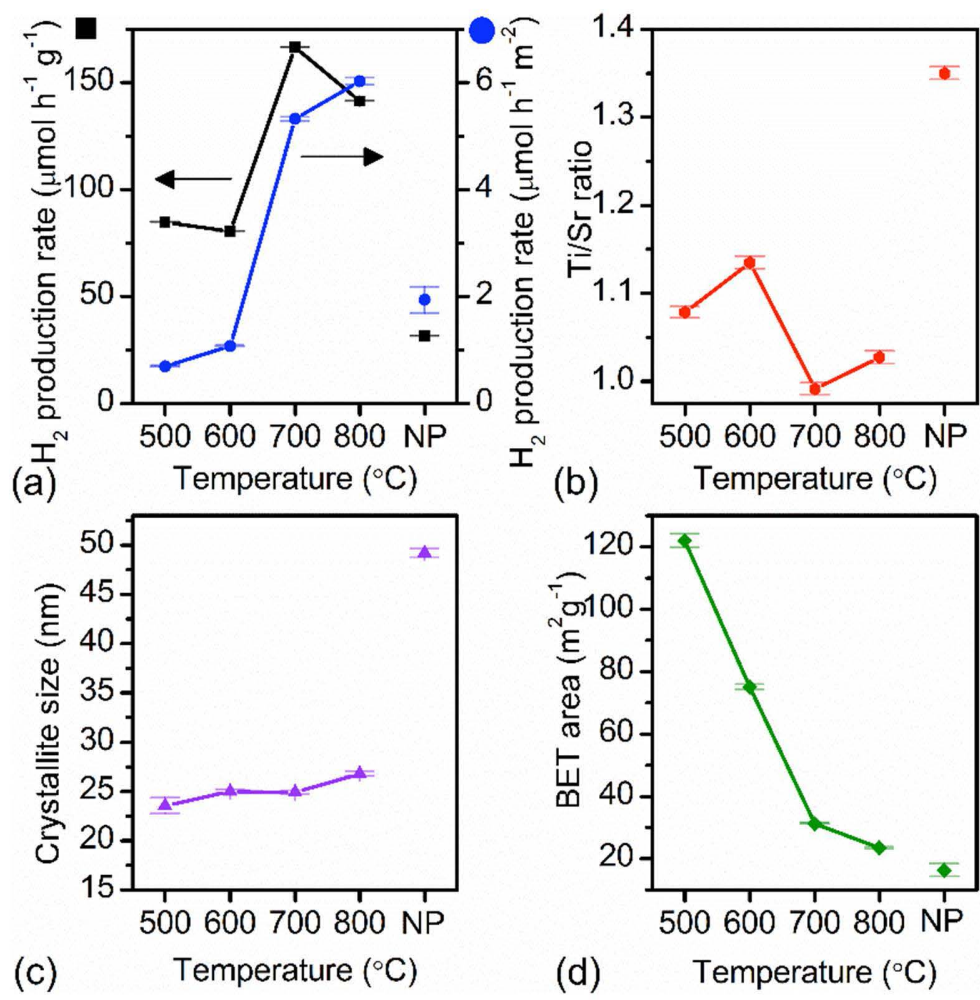

FIG. 4. (a) Hydrogen production rate, (b) titanium to strontium ratio, (c) crystallite size, and (d) BET surface area of the electrospun nanofibers calcined at $500,600,700$, and $800{ }^{\circ} \mathrm{C}$, and of the NP sample. Error bars are indicated. 


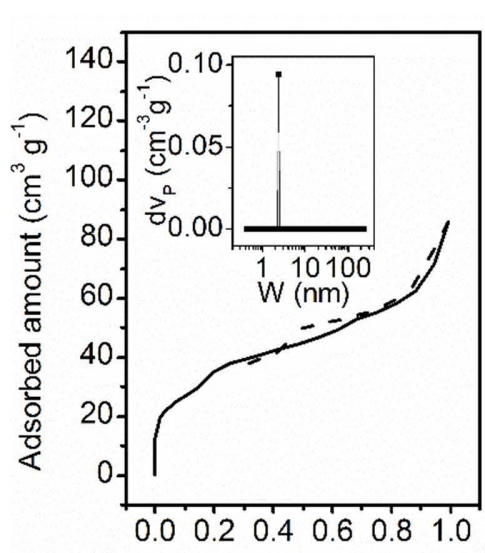

(a)

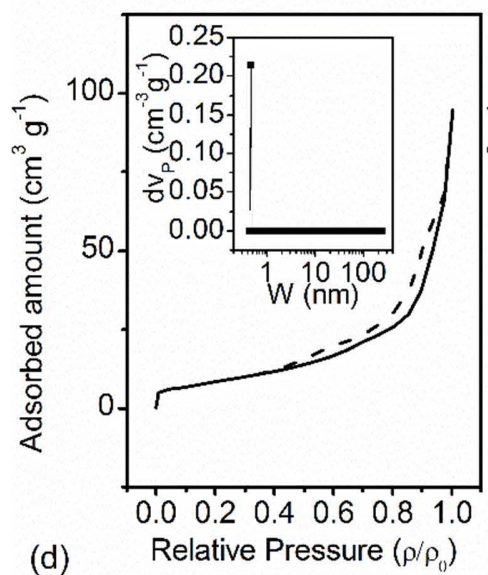

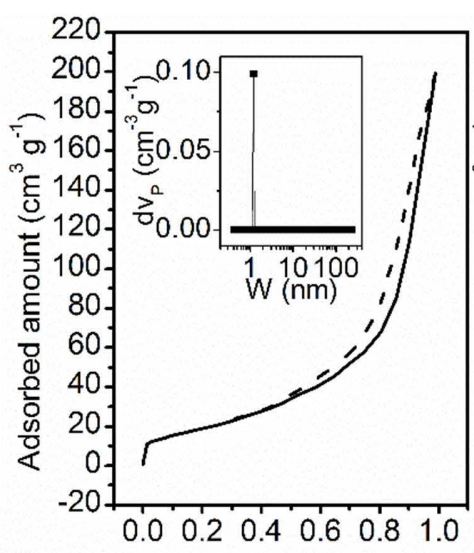

(b)

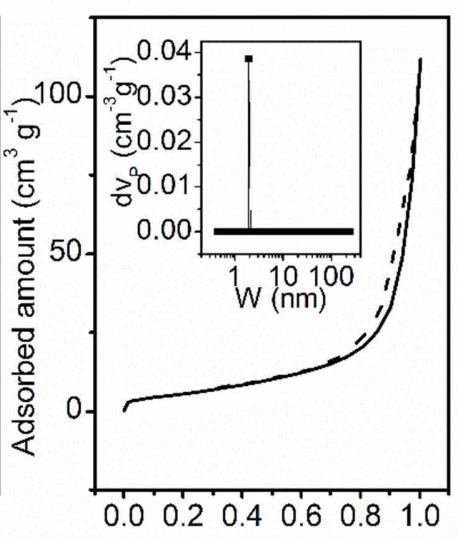

(c)

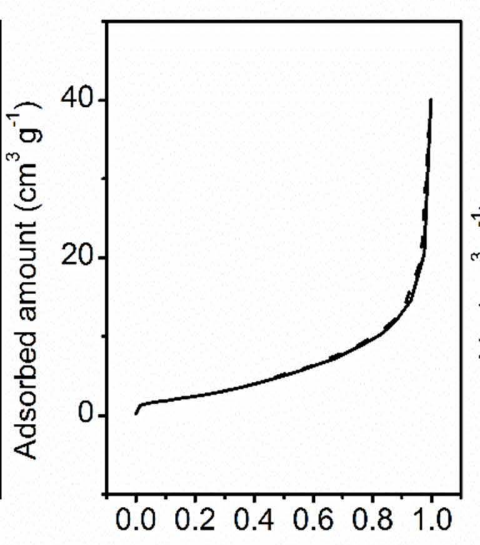

(e) Relative Pressure $\left(\rho / \rho_{0}\right)$

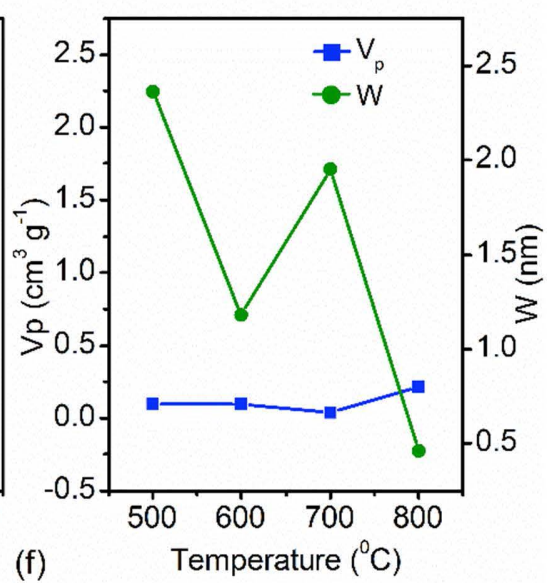

FIG. 5. Nitrogen adsorption (solid black line) - desorption (dashed black line) isotherms of the electrospun nanofibers calcined at (a) 500, (b) 600 , (c) 700 , and (d) $800{ }^{\circ} \mathrm{C}$, and (e) of the NP sample. The computed pore volume $V_{P}$ and the slit widths $W$ for the mesoporous nanofibers are shown in (f) using NLDFT analysis (inset). 


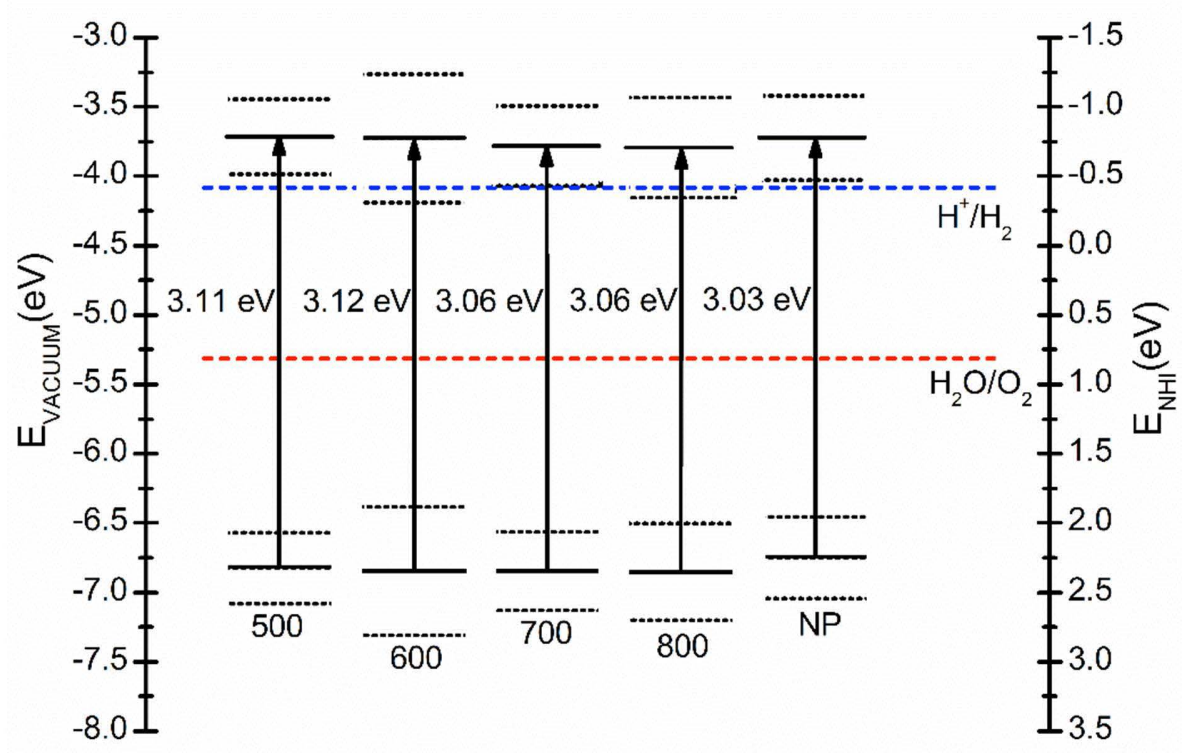

FIG. 6. Band diagrams of the electrospun nanofibers calcined at 500, 600, 700, and $800{ }^{\circ} \mathrm{C}$, and of the NP sample. The reduction-oxidation potential levels of hydrogen (blue dashed line) and oxygen (red dashed line) at $\mathrm{pH}=7$ are also indicated. The valence band levels are estimated from photo-electron yield spectra in air, errors are indicated as black dotted lines. The conduction band levels are determined from the valence band levels and the estimated $E_{g}$, errors (black dotted line) are also indicated. 

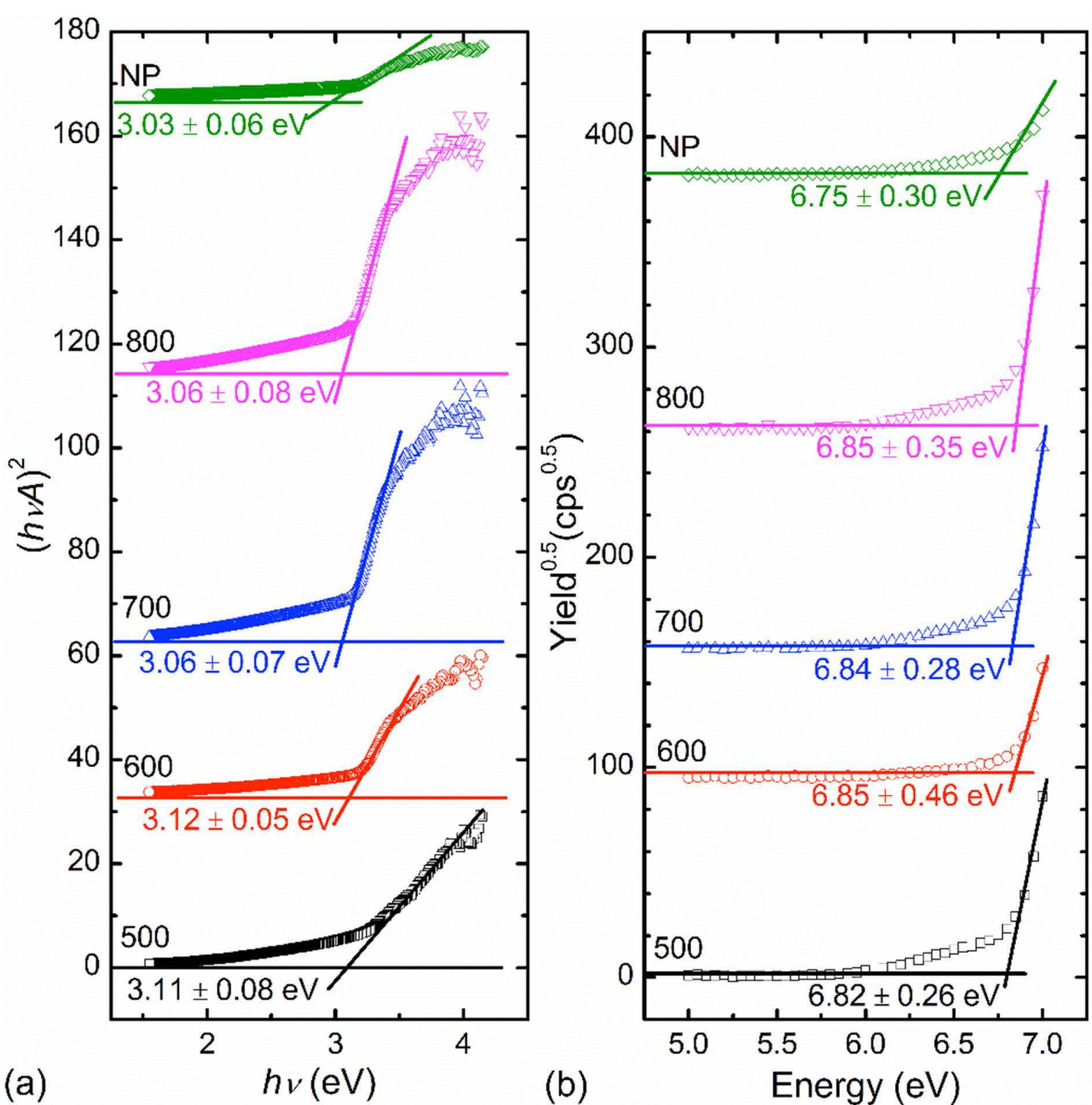

FIG. 7. (a) Plots of $(h v A)^{2}$ versus energy derived from the absorbance spectra and (b) photoelectron yield spectra obtained under air atmosphere for the nanofibers calcined at 500,600, 700 , and $800{ }^{\circ} \mathrm{C}$, and for the NP sample. The estimated $E_{g}$ from the Tauc plot and the estimated valence band level estimated from the photo-electron yield spectra are also indicated. 